\title{
IMPROVING SERVICES IN OUTDOOR PATIENT DEPARTMENTS BY FOCUSING ON PROCESS PARAMETERS: A SIMULATION APPROACH
}

\author{
Sanjay Verma \\ Indian Institute of Management \\ Vastrapur, Ahmedabad \\ Ahmedabad 380015, INDIA
}

\author{
Ashish Gupta \\ Department of Mechanical Engineering \\ IIT Mumbai, Powai \\ Mumbai 400076, INDIA
}

\begin{abstract}
The paper examines working of outdoor patient departments in a general hospital. There are several inpatient wards and out-patient departments and hundreds of patients visited the hospital daily for treatment. The place is chaotic and noisy, especially in the morning. The current performance is evaluated and newer ways are identified to measure the performance of the hospital. Various alternatives are evaluated by simulating each of them. As against the commonly held view that there is a shortage of staff in the hospital, it is actually a problem of maintaining discipline and scheduling of staff. Further, there is a need to change the way activities are performed. The paper also suggests ways of measuring process oriented performance of Outdoor Patients Department (OPD) and OPD registration counters.
\end{abstract}

\section{INTRODUCTION}

The public health delivery in India is in very bad shape. A large part of blame is laid on the low spending on health infrastructure. This is further aggravated by the fact that service orientation is very low in government hospitals. In fact, the process of measuring service quality does not exist in public hospitals. There are several reasons for this. Firstly, there is no pressure to perform, either from customer or superiors. Quite often, patients from lower income groups are the only ones who visit government hospitals. Their expectations are so low that any service as long as it is available is acceptable. Secondly, the administrative staff in government hospitals are not trained in management and do not understand fundamental principles of management in operations, finance, or human resources. The absence of the management knowledge makes it difficult for them to conceive better solutions. Thirdly, government hospitals are yet to introduce the concept of benchmarks. In absence of benchmark and performance management systems, no comparison of services can be done within various wards and departments in a hospital or between various hospitals.

The hospital in consideration is located in the state of Gujarat, India. It has a capacity of 250 beds in inpatient wards. It caters to approximately 1200 patients on average on any given day in the outdoor patients departments (OPDs). OPD provides services to those patients who are not required to be admitted to hospital. They are given medicines and are required to visit again as requested or required by the doctor. Staff shortage in the hospital is a major concern for the employees in the hospital. Given the increase in patient traffic, the only feasible option is to look for ways and suggest means by which the performance of the system could be improved. In this case, we focus on OPD, as it is the section where the hospital experiences heavy load. The motivation for this work was:

1. To identify parameters on which performance of OPDs can be measured;

2. To study and compare the performance of various OPDs in the hospital;

3. To identify alternatives by which performance can be improved. 
Verma and Gupta

\section{LITERATURE SURVEY}

Huarng and Lee (1996) deal with the issue of overwork and overcrowding in in an out-patient department of a local hospital in Chia-Yi in Taiwan. The study focused on the utilization of doctors and staff in the out-patient department, the time spent in the hospital by an out-patient, and the length of the out-patient queue. The paper explains a computer simulation model with changes in appointment system, staffing policies and service units would affect the observed bottleneck. Hunt et al. (2008) examine the importance of early treatment in medical emergencies for pediatric and cardiopulmonary cases. Based on observational study, they report that significant delays and communication error take place and focus should be given to avoid these while educating the medical staff. Xiao et al. (2009) examine the medical emergencies and propose a framework to modify the workflow. They suggest that by downgrading lower priority jobs and combining separate processes can shorten patient total waiting time in the emergency department.

Joshi (2008) simulated the emergency department using discrete event simulations modeling using ARENA 10.0 software. With different arrival patters and service time durations the model helps to estimate the resource requirements. Ghosh and George (2006) have developed a computer based physician requirement model that helps to generates activity-wise and overall physician requirements. The software helps to conduct scenario analysis by changing utilization levels.

Kumar (2011) use system simulation for finding out the optimal bed capacity according to patient flow of emergency and routine patients. Ma and Demeulemeester (2010) discuss the issue of surgical inpatients who are given alternative ward as there is a bed-shortage in the original ward. They use patient misplacement as the main performance indicator of service level. Chen et al.(2010) study capacity allocation model from the perspective of revenue management by using two-class and multi-class capacity allocation models.

\section{THE HOSPITAL}

The hospital under study is headed by a medical superintendent (MS). Patients are either given treatment in the OPDs or admitted in wards. It is a multi-specialty hospital, commissioned in 1971 and currently has a with a bed capacity of 250 .

There are twelve OPD (including medical, obstetrics, orthopedics etc.), nine indoor wards (including medical, surgery, gynecology etc.) and five operation theaters (including surgery, gynecology, orthopedics, etc.). Amongst all the sections, it was the OPD that attracted a maximum number of patients on daily basis. Figure 1 shows the process of OPD. The following sections provide details of OPDs.

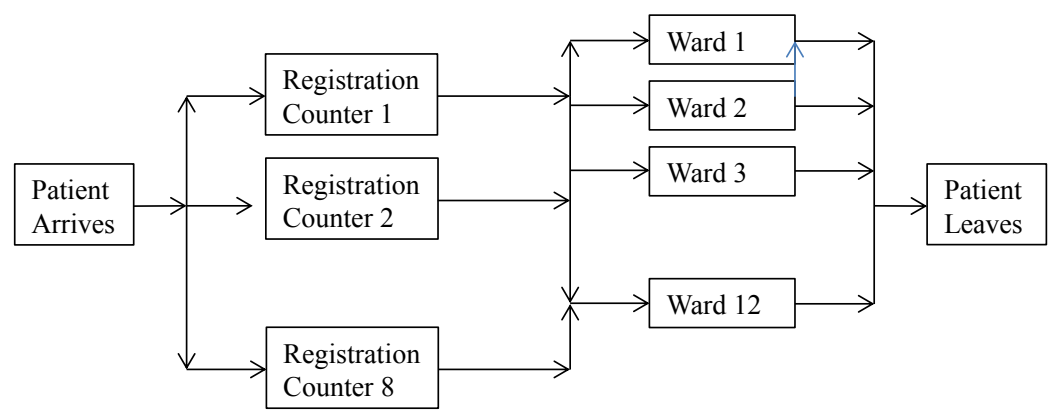

Figure 1: Flowchart of OPD process in the hospital. 
Verma and Gupta

\subsection{Registration Counters}

This is the place where the registration of patients takes place. There are eight general counters and one emergency counter. The OPD section works full day from Monday to Friday and half a day on Saturday. The general counters are open from 8.30 AM to 11.30 AM in morning and 2.30 PM to 4.00 PM in afternoon. The emergency counter is open 24 hours. Each registration counter is allotted to patients pertaining to a particular set of OPDs. For example, patients with skin, eye, and tuberculosis (old cases) go to counter 1 , while those with general medical problems, skin, gynecology, tuberculosis (new cases) go to counter 2 and so on. Table 1 gives the registration counter number and corresponding OPDs which they serve. For each patient visiting the OPD, a case-file (manual, paper based) is prepared, in which the patient's history is maintained. The case-file is stored in the hospital itself (at the registration counter). For new patients, a fresh case-file is opened, while for old patients, the file is taken out from storage, according to a registration number allotted on the first visit. Patients present their case to doctors of their departments and after their check-up return the case-file to the nurse present at the respective OPD. These case-files are collected at the end of the day and filed at the registration counters. These would be used when patients visited the hospital the next time.

Table 1: Distribution of patients to various counters.

\begin{tabular}{|l|l|l|l|}
\hline $\begin{array}{l}\text { Reg. } \\
\text { Counter } \\
\text { No. }\end{array}$ & List of OPDs served & $\begin{array}{l}\text { Reg. } \\
\text { Counter } \\
\text { No. }\end{array}$ & List of OPDs served \\
\hline 1 & Skin, Eye, Tuberculosis (old cases) & 6 & Gynecology, ENT (old cases) \\
\hline 2 & $\begin{array}{l}\text { Medical, Skin, Gynecology, tubercu- } \\
\text { losis (new cases) }\end{array}$ & 7 & $\begin{array}{l}\text { Paediatric, Dentistry, Psychiatry, Ayur- } \\
\text { veda, Eye (new cases) }\end{array}$ \\
\hline 3 & Medical (old cases) & 8 & $\begin{array}{l}\text { Paediatric, Dentist, Psychiatry, Ayurveda } \\
\text { (old cases) }\end{array}$ \\
\hline 4 & $\begin{array}{l}\text { Orthopaedics, Surgical, ENT (new } \\
\text { cases) }\end{array}$ & 9 & Emergency cases. \\
\hline 5 & Orthopaedics, Surgical (old cases) & & \\
\hline
\end{tabular}

The counters are supposed to be managed by thirteen staff members that include a supervisor. However, only eight persons are posted to manage the nine counters, of which five people works during normal hours and three people works during off-shifts on emergency counters. One staff member manages an emergency window. Therefore, the eight registration counters are manned by the four persons. The OPD supervisor frequently helps the subordinates in managing the windows. According to the OPD supervisor, "We lack at least four clerks and a class III employee in the OPD section".

\subsection{Out-Patient Departments}

A separate OPD existed for each category of illness. Consultant doctors who hold higher qualifications, such as Master of Surgery or Doctor of Medicine are expected to provide treatment in OPDs. However, general medical practitioners (GMP) who are M.B.B.S and resident doctors (post-graduate medical students on training) also treat in these OPDs. Medical, surgery, orthopedics and gynecology OPD have two units operating on alternate days. In rest of the OPDs all consultants operate throughout the week. The number of consultants varies from one to three for any day.

The scheduled arrival time of doctors is 9.00 AM but they usually arrive at 9.30 AM. Before 9.30 AM, doctors spent time in the in-patient's wards, examining the patients admitted there. The OPD visit timings end at 12.30 PM in the afternoon. In between this period the doctors take a break of 30 minutes at 11.00 AM approximately. This was referred to as recess time in the hospital. However, the break did not have any official sanction. 


\section{Verma and Gupta}

According to a senior officer the recess break had continued there since long. Since it is a regular trend to have the break, there hadn't been any actions to stop it. It was accepted as a routine practice.

For the afternoon shift, registration starts at 2.30 PM, whereas doctors arrive at 3.30 PM (in some cases at 3.40 PM) and work up to 4.00 PM (sometimes 4.15 PM). The time taken for doctors to treat patients depends on illness. The average time taken per patient for medical OPD is 2.85 minutes, for orthopedics 3.05 minutes, skin 2.65 minutes, surgery 2.95 minutes, TB 2.53 minutes, genecology 6.33 minutes and dentist 2.6 minutes. The average time was computed by taking a sample of 50 patients for each OPD.

\subsection{Patient's Arrival}

There is a lot of variation in the number of patients arriving each hour. Since registration starts at 8.30 AM, patients start coming from 8.00 AM. There is a constant and steady arrival of patients up to 9.30 AM. A large number of patients come for medical, orthopedics, surgical, and skin OPDs. This results in long queues during peak times at counter numbers 2 and 4 respectively. On any particular day maximum patients (nearly 44\%) come between $9.30 \mathrm{AM}$ to $10.30 \mathrm{AM}$ windows, while approximately $20 \%$ come in between 8.30 AM to 9.30 AM. Only 16\% patients come in the evening shift of 15.30 PM to 16.00 PM.

The staff is unable to manage the counters effectively. One could observe long queues of patients during this period. Since eight counters are managed by four to five staff, the OPD staff work in a haphazard manner moving from one counter to another in this period. From 10.30 AM to $11.30 \mathrm{AM}$, it is lean time when most counters remain free. The afternoon slot sees patients queuing up from 2.00 PM while the registration starts at 2.30 PM, patients after the registration move to OPDs for check-up.

\subsection{Opinion of Employees}

In a meeting with the authors, one of the doctors said: "Since we have to visit indoor wards we are unable to devote enough time to patients. Further, there is shortage of doctors, adding to the problem." Another doctor suggested, "Many other civil hospitals in Gujarat have adopted computers for patient records management; however, we are yet to make use of technology. If one visits the civil hospital at Surat in Gujarat, a doctor need not write on any paper. The entire hospital is paperless. Everything happens so fast for the patient. We should also computerize our process to give efficient services to our patients." The MS shared, "Our hospital is performing very well. The quality of service is very good. If you look at the percentage of deaths in emergency cases, the numbers are very low. We have been able to save a lot many

lives. We would have done better, but most of the patients who come to us were already in a very serious condition". However, she felt that there were opportunities for improvement, "I want to improve the services given to patients from the doctors' side,"

\section{OBSERVATIONS AND ANALYSIS}

\subsection{Data Collection}

The data of number of patients for various illnesses was collected from registration counters. The data for arrival patters of patients, the time taken at registration counters and at wards was collected by direct observation for one week period. Long queues were visible at the registration counter during the peak hours of 9.30 AM to 10.30 AM and this often resulted in a chaotic situation. The queue often exceeded 30 persons in some of the counters. Lack of adequate manpower at the registration counters resulted in this.

Queues of patients were noticeable in the OPDs, waiting to be seen by doctors. These were significantly longer in the OPDs such as medical, orthopedics; surgery, and skin. Moreover, these departments constitute $65-70 \%$ of the total incoming patients. The average waiting time in the treatment wards was 35 minutes, whereas it rose to more than 1 hour during the busy period. 


\section{Verma and Gupta}

The recess time, as mentioned earlier, refers to the time period of half an hour, ranging from 11.00 AM to $11.45 \mathrm{AM}$, when most of the doctors either in groups or individually take a tea break outside the corridors of hospital. This break was taken by almost all the doctors in the hospital. This break also resulted in long queues in OPDs. A senior officer said that the number of doctors in the hospital was much less than what was required. He felt that it was quite difficult for the hospital to survive with this staff. Many nurses had a common complaint that the doctors tend to take break from work at will; it is they who had to work continuously without rest.

The arrival pattern of patients was observed for one week. Fifty patients were shadowed to understand the time spent at each station. In the simulation, the patient arrival was simulated in the same patteras that observed in real situation.

\subsection{Calculations on Existing System}

Based on the data collected, we calculated the aggregate utilization of doctors in OPDs on a day-to-day basis. It was found that except for few cases on certain days, the utilization of doctor's time was far below $100 \%$. We assumed that out of 300 minutes available on every day from Monday to Friday, doctors devote 180 minutes in OPDs. Rest of the time was assumed to be spent for various in-patient wards. On Saturdays, out of 180 minutes available, 120 minutes were assumed to be spent on OPDs.

It was seen that in most of the cases, even at 180 minutes of availability, the utilization rate of doctors is below $100 \%$. This negates the belief that more doctors are required in the hospital. In cases where the utilization was above $100 \%$, we increased the time available to 240 minutes and 300 minutes respectively to see the utilization. On Saturday, the time available data used was 144, 192 and 240 minutes respectively. It can be inferred that the shortage of doctors exists only in certain departments on certain days in a week. Overall, there is no shortage of doctors in the hospital.

\section{NEW PROCESS MODELS AND SIMULATED SOLUTIONS}

These observations called for a detailed analysis of the system and to determine the alternatives that exist. For this purpose, modeling software was used. We model, simulate, and present the results of the existing system and four alternative scenarios building upon the existing one. Arrival of patients was simulated based on the data collected unless stated otherwise for a particular scenario. Further, the proportion of patients with various illnesses was generated in proportion to actual data as observed. One hundred simulation runs of each model were conducted. Various alternatives that have been simulated are as follows:

1. Existing Scenario (ES): The way hospital works currently.

2. Token System (TS): In this scenario, patients will be given a token on their arrival. The token indicates their sequence in the queue. They can get registration details from any registration counter.

3. Token System without break (TSWB): In addition to the change in scenario 2, the doctors will be available without any break between 11.30 to $12.00 \mathrm{pm}$.

4. Token system without break and extended registration time (TSWBERT): In addition to scenario 2 , the registration counters will be open up to 13.00 PM., additionally; the registration counters will open at 15.20 in afternoons.

5. Token system without break, delayed start and extended registration time (TSWBDSERT): In this scenario, the registration will start at 09.20 AM instead of 08.30 AM and would continue up to 13.00 PM. There shall be a break of 30 minutes in between. Additionally, the registration counters will open at 15.20 in afternoons.

The motivation for the above scenarios was that minimum change should be brought in the working of doctors, as they were very resistive to change. Their cooperation is essential for the successful change. We assume that the responsible persons would be able to change the process as required. 


\section{Verma and Gupta}

Various parameters that were measured in the experimentation were as follows:

1. Time spent and Queue lengths;

2. Resource utilization;

3. Work in Progress.

Results from all scenarios for parameter have been tabulated together to facilitate easy comparison.

\subsubsection{Time Spent and Queue Lengths}

In the process, examination by doctor is considered to be a value-add-activity as patients come for this particular requirement. Registration is considered to be non-value-add as it is required by the hospital and is not a need of the patients.

As none of the scenarios modified any value-add or non-value-add activity, results from all the scenarios were the same, as presented in Table 2. It can be seen that non-value-add time and value add time remain approximately the same in all five cases. The difference is observed in waiting times. The average waiting time reduces significantly in the case where the registration counters are opened at 9.20 AM instead of 08.30 AM.

Table 2: Aggregate time taken in various scenarios.

\begin{tabular}{|l|r|r|r|r|r|}
\hline & \multicolumn{1}{|c|}{ ES } & \multicolumn{1}{c|}{ TS } & TSWB & TSWZBERT & TSWBDSERT \\
\hline $\begin{array}{l}\text { Non-Value-Add } \\
\text { Time }\end{array}$ & 1.33 & 1.33 & 1.33 & 1.34 & 1.33 \\
\hline Value-Add Time & 2.89 & 3.02 & 3.02 & 3.02 & 3.02 \\
\hline Waiting Time & 25.28 & 24.71 & 24.71 & 27.78 & 13.51 \\
\hline $\begin{array}{l}\text { Total Time: Over- } \\
\text { all Average }\end{array}$ & 29.51 & 29.06 & 29.06 & 32.13 & 17.86 \\
\hline $\begin{array}{l}\text { Total Time: Max- } \\
\text { imum Average }\end{array}$ & 49.60 & 42.94 & 42.94 & 58.42 & 36.64 \\
\hline $\begin{array}{l}\text { Total Time: Min- } \\
\text { imum Average }\end{array}$ & 19.58 & 20.52 & 20.52 & 15.74 & 10.21 \\
\hline
\end{tabular}

From Table 3, it can be seen that extended registration time will have significant impact on reduction in waiting time at registration counters. Similarly late start of registration will have impact on waiting time at wards. Similar impact can also be seen in maximum waiting times. It is a counter-intuitive and yet very important observation; late start of a service will improve performance of the system rather than its early start.

\subsubsection{Resource Utilization}

The utilization of doctors in wards goes down in scenario 3,4 and 5 as the doctors work without break and hence total time available increases. Various scenarios bring a change in the utilization at registration counters. Introduction of token system reduced the variability at registration counters and brings its utilization to similar levels at all the counters. Table 4 shows the utilization of doctors in wards and Table 5 shows utilization at registration counters. 


\section{Verma and Gupta}

Table 3: Time taken in various scenarios at registration counters and wards.

\begin{tabular}{|l|r|r|r|r|r|}
\hline Item & \multicolumn{1}{|c|}{ ES } & \multicolumn{1}{c|}{ TS } & \multicolumn{1}{c|}{ TSWB } & TSWZBERT & TSWBDSERT \\
\hline $\begin{array}{l}\text { Registration Coun- } \\
\text { ters :Average }\end{array}$ & 9.28 & 6.15 & 6.15 & 1.05 & 9.28 \\
\hline $\begin{array}{l}\text { Wards: } \\
\text { Average }\end{array}$ & 16.43 & 17.99 & 17.99 & 25.46 & 2.56 \\
\hline $\begin{array}{l}\text { Registration Coun- } \\
\text { ters :Maximum }\end{array}$ & 72.00 & 44.00 & 44.00 & 13.00 & 51.00 \\
\hline Wards: Maximum & 61.00 & 63.00 & 63.00 & 63.00 & 19.00 \\
\hline
\end{tabular}

Table 4: Utilization of doctors in wards.

\begin{tabular}{|l|r|r|r|r|r|}
\hline Ward Name & ES & TS & TSWB & TSWZBERT & TSWBDSERT \\
\hline Ayurveda & $24 \%$ & $24 \%$ & $18 \%$ & $20 \%$ & $20 \%$ \\
\hline Dentist & $56 \%$ & $57 \%$ & $41 \%$ & $48 \%$ & $48 \%$ \\
\hline ENT specialist & $32 \%$ & $71 \%$ & $52 \%$ & $60 \%$ & $59 \%$ \\
\hline Eye & $50 \%$ & $50 \%$ & $37 \%$ & $43 \%$ & $42 \%$ \\
\hline Gynecology & $40 \%$ & $40 \%$ & $30 \%$ & $34 \%$ & $33 \%$ \\
\hline Medical & $47 \%$ & $47 \%$ & $34 \%$ & $40 \%$ & $39 \%$ \\
\hline Orthopedic & $42 \%$ & $42 \%$ & $31 \%$ & $36 \%$ & $36 \%$ \\
\hline Pediatrics & $38 \%$ & $37 \%$ & $27 \%$ & $33 \%$ & $32 \%$ \\
\hline Psychiatric & $32 \%$ & $30 \%$ & $23 \%$ & $26 \%$ & $25 \%$ \\
\hline Skin & $25 \%$ & $25 \%$ & $19 \%$ & $21 \%$ & $21 \%$ \\
\hline Surgical & $39 \%$ & $38 \%$ & $28 \%$ & $33 \%$ & $33 \%$ \\
\hline TB & $18 \%$ & $17 \%$ & $12 \%$ & $14 \%$ & $15 \%$ \\
\hline
\end{tabular}

Table 5: Utilization at registration counters.

\begin{tabular}{|l|r|r|r|r|r|}
\hline $\begin{array}{l}\text { Counter } \\
\text { Number }\end{array}$ & ES & TS & \multicolumn{1}{|c|}{ TSWB } & TSWZBERT & TSWBDSERT \\
\hline 1 & $13 \%$ & $14 \%$ & $10 \%$ & $17 \%$ & $17 \%$ \\
\hline 2 & $25 \%$ & $14 \%$ & $10 \%$ & $17 \%$ & $17 \%$ \\
\hline 3 & $17 \%$ & $14 \%$ & $10 \%$ & $17 \%$ & $17 \%$ \\
\hline 4 & $26 \%$ & $14 \%$ & $10 \%$ & $17 \%$ & $17 \%$ \\
\hline 5 & $22 \%$ & $14 \%$ & $10 \%$ & $17 \%$ & $17 \%$ \\
\hline 6 & $8 \%$ & $13 \%$ & $10 \%$ & $17 \%$ & $17 \%$ \\
\hline 7 & $15 \%$ & $14 \%$ & $10 \%$ & $17 \%$ & $17 \%$ \\
\hline 8 & $9 \%$ & $17 \%$ & $10 \%$ & & \\
\hline
\end{tabular}




\subsubsection{Work in Progress}

The work-in-process in the system is measured in terms of number of patients present in the hospital at a given point of time. As it can be seen in Figure 2, the peak number of patients are in existing system as well as, token system at 218 . The peak is lowest when the doctors work without taking a break and registration time is extended. While the peak increases with delay in opening of registration window, it remains for very short period.

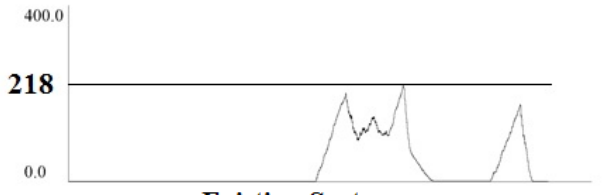

Existing System
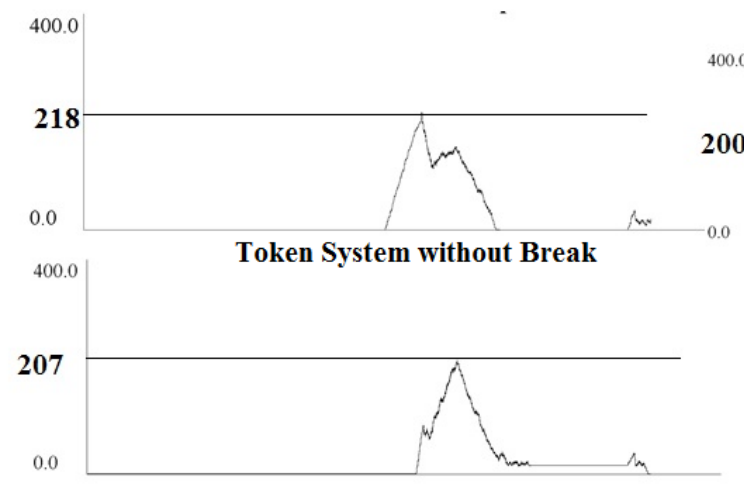

Token System without Break, Delayed Start and Enhanced Registration Time
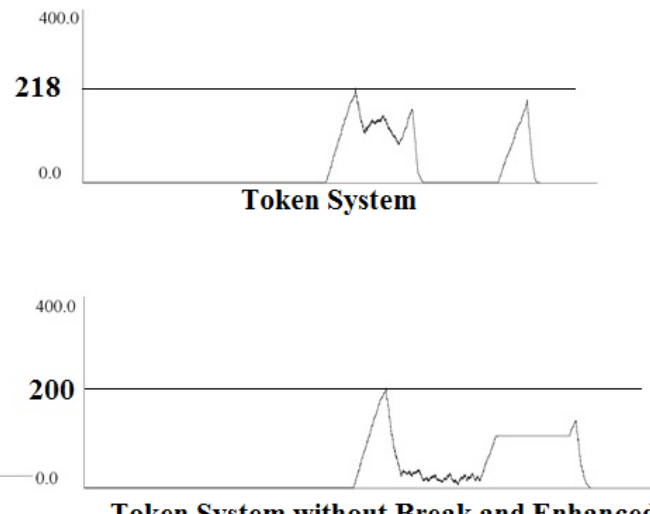

Token System without Break and Enhanced Registration Time

Figure 2: Number of patients in hospital under various scenarios (No. of patients vs. time).

As seen in Figure 3, the removal of break at 11.00 AM brings significant impact in peak load at wards. Further, delay in opening of registration window also balances the load significantly. Figure 4 shows the impact of various scenarios at registration counters. Introduction of token system balances the load at registration counters. If registration time window is expanded, it will further balance the peak load. Delay in opening of registration window, will increase the peak load at registration counters, though it will balance the load in wards.

\section{VALIDATION}

The simulated data was validated by collecting actual observation. Following checks were made.

1. The number of patients arriving should be same as the real scenario and proportion of patients of each illness type should also be same.

2. The number of doctors available should match the availability in the hospital.

3. The time taken at each station should be according to the distribution observed.

As mentioned data was collected in all the wards, and registration counters to observe real distributions. Fifty patients were shadowed to check that the simulated data match with the observed data. 


\section{Verma and Gupta}

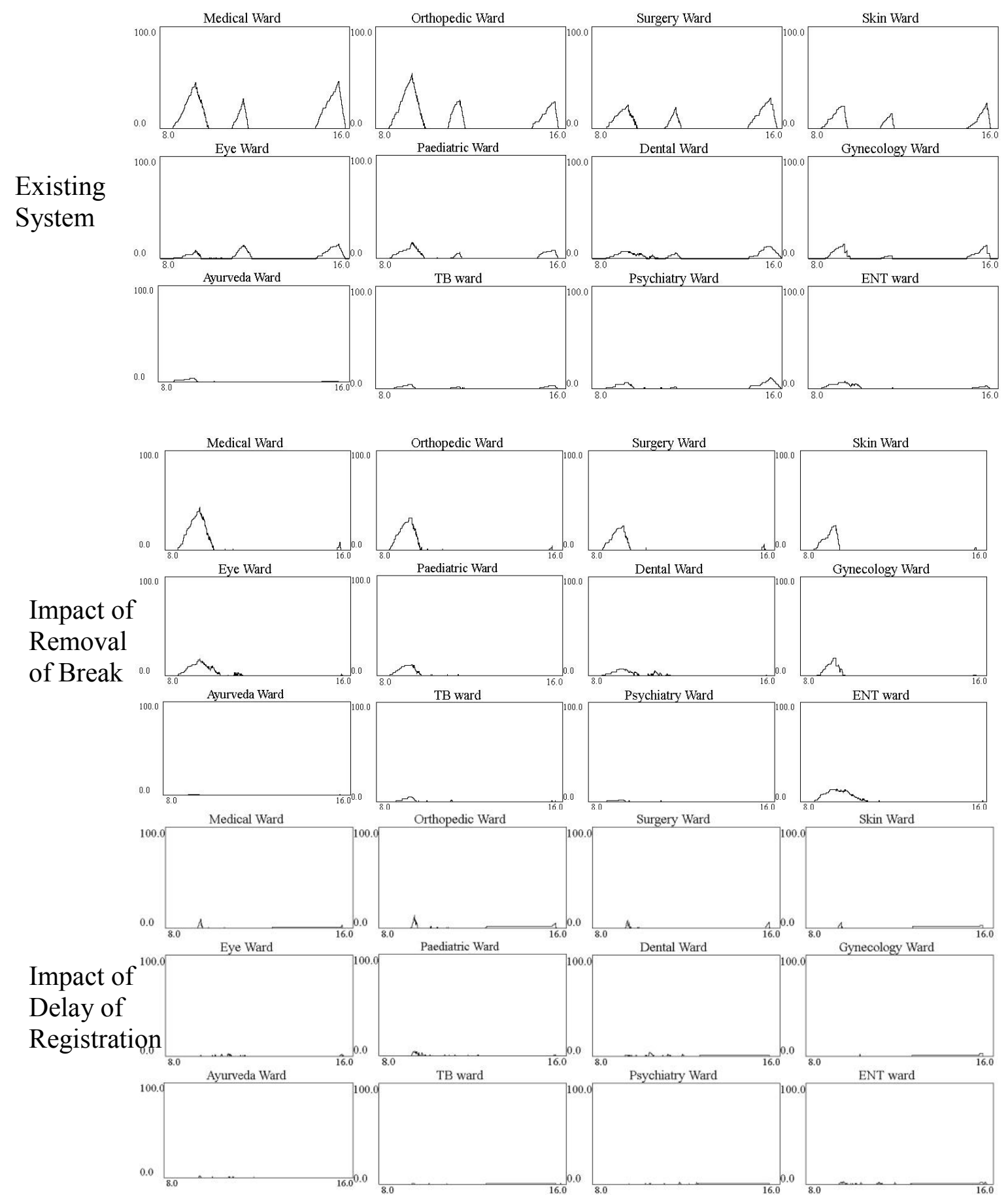

Figure 3: Patient load in various wards (no. of patients vs. time). 


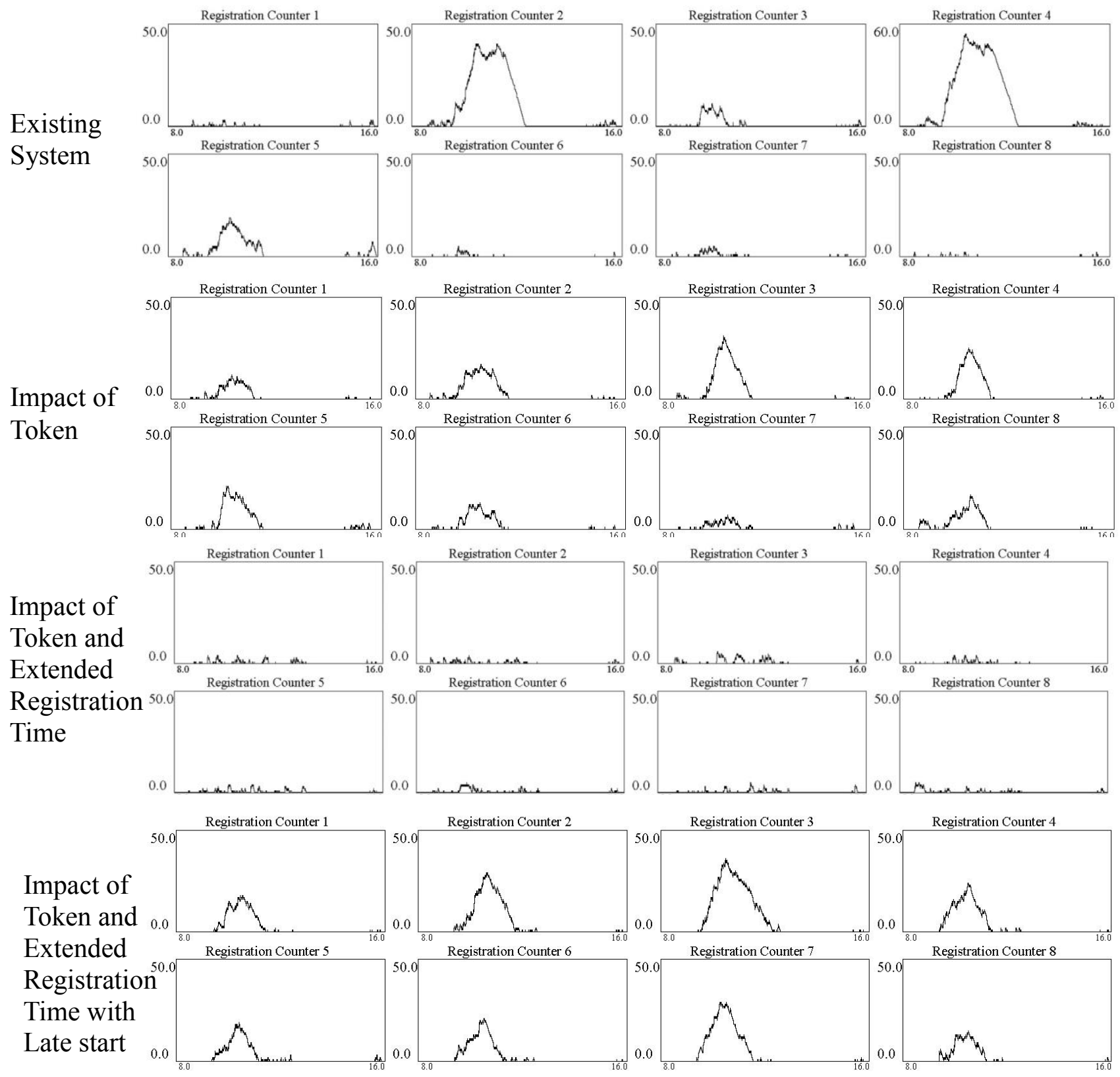

Figure 4: Patient load at registration counters (no. of patients vs. time).

\section{IMPLICATIONS AND LESSONS}

The lessons learnt from the above study and simulations are as follows: 


\section{Verma and Gupta}

\subsection{Identify and Measure Process Parameters}

Quite often, hospitals develop detailed financial parameters (such as operating profit/costs, cost per operation, cost per patient etc.) and output oriented parameters such as number of surgeries conducted, number of patients seen in OPDs, etc. However, there is a need to emphasize on process oriented parameters. While financial parameters keep a track of the monetary health of the hospital and output parameters indicate contribution to society, process indicators inform us of the level of service received by patients. Only when we focus on process parameters, we realize that we may not be giving efficient service to patients. Further, hospitals usually complain of lack of infrastructure in absence of funds; process changes do not take significant investment. As seen in the above experiment, such changes can be brought by minimal or no investment.

\subsection{Identify Bottlenecks and Remove them}

The task of management in hospital is to continuously identify activities that act as bottlenecks in the flow of patients and take proactive actions to remove them. It is important to note that whenever bottlenecks are removed from one location, newer bottlenecks are created at other places. Therefore, it becomes a continuous process rather than a one-time process. Bottlenecks can be removed in multiple ways:

1. By improving efficiency of the activity;

2. By making that activity as a needless one and thereby dropping it completely;

3. By augmenting capacity of the resources available to perform the activity.

\subsection{Resource Shortage May Be Momentary and Not Regular}

Quite often, complaints of shortage of resource are not genuine. They may be results of poor planning, inefficient management or lack of desire on part of service providers to change. Proper study of capacity requirement and resource availability should be done. The result should be communicated to everyone in the organization. This should be the basis of the improvement process. For example, in the hospital, doctors and staff complain about shortage of personnel. However, the real problem is variability in demand and not resource availability.

\subsection{Avoid Special Purpose Counters}

Many times, certain service counters are reserved for certain classes of population or certain types of disease. Such practices bring down the overall efficiency of the system. Counters should be multipurpose and should serve all patients or patients with any disease (unless a specialized server is required by design such as OPDs). In case, there is need to provide specialized or faster services to ladies, patients with particular illness, emergency service, etc. it is always better to give out-of-turn priority to such patient, rather than creating special facilities.

\subsection{Business Process Reengineering Should Necessarily Precede Information Technology Implementations}

As seen in the above example, doctors actively suggested use of information technology (IT) to improve processes in the hospital. However, as seen by from the study, IT will not improve performance on any dimension, unless basic changes at the process level are introduced. As we may note that patient is provided service at two stations, registrations counter and ward, which take time of 1.33 and 2.89 minutes respectively. Any computerization will just reduce this time only which is negligible time out of total time, a large part of which is waiting time. It is a common knowledge that any IT implementation should follow business process reengineering (BPR) exercise. Computerization of poor processes increases the inefficiency of the system. 


\section{Verma and Gupta}

\subsection{Customer Comfort Should Be Focused}

The exercise points out the fact about how little consideration is shown to customer service. There is need to focus on patients. One of the widespread methods to measure customer service is patient surveys. However, we believe that in public hospitals of developing countries like India, which serve lowers strata of society, citizens are so much accustomed to service with poor quality, that they do not complain. In such cases, hospitals should identify benchmarks and try to surpass them.

\section{CONCLUSIONS}

In this paper, we have measured the load on various OPDs in a hospital and identified the bottlenecks in the system. As against the commonly held view that there is a shortage of staff in the hospital, it is actually a problem of maintaining discipline and scheduling of staff. Further, there is a need to change the way activities are performed. We also show that by reducing unevenness in demand, we can deliver better services. We also suggest ways of measuring process oriented performance of OPDs and OPD registration counters. Finally, we simulate the system with existing models and other alternative models and demonstrate the change in the behavior of the system.

\section{REFERENCES}

Chen, C., Y. Zhu, T. Zhu, and Q. Lin. 2010. "Capacity Allocation Model and Its Application in Community Hospital Ward Management." Journal of Tsinghua University Science and Technology 50 (6): 961-964.

Ghosh, B., and C. George. 2006. "Computer-assisted Physician Requirement Planning." Journal of Health Management 8 (1): 157-166.

Huarng, F., and M. H. Lee. 1996. "Using Simulation in Out-patient Queues: a Case Study." International Journal of Health Care Quality Assurance 9 (6): 21-25.

Hunt, E. A., A. R. Walker, D. H. Shaffner, M. R. Miller, and P. J. Pronovost. 2008. "Simulation of Inhospital Pediatric Medical Emergencies and Cardiopulmonary Arrests: Highlighting the Importance of the First 5 Minutes." Pediatrics 121 (1): e34-e43.

Joshi, A. J. 2008. "Study on the Effect of Different Arrival Patterns on an Emergency Department's Capacity Using Discrete Event Simulation". Kansas State University.

Kumar, S. 2011. "Modeling Hospital Surgical Delivery Process Design Using System Simulation: Optimizing Patient Flow and Bed Capacity as an Illustration." Technology and Health Care 19 (1): $1-20$.

Ma, G., and E. Demeulemeester. 2010. "Assessing the Performance of Hospital Capacity Planning Through Simulation Analysis." Available at SSRN 1749312.

Xiao, N., S. Dutta, R. Sharman, and H. R. Rao. 2009. "A Simulation Based Study in a Hospital Emergency Department: Capacity and Workflow Issues.” AMCIS 2009 Proceedings. Paper 495.

\section{AUTHOR BIOGRAPHIES}

SANJAY VERMA is an Associate Professor in the Computer and Information Systems Group at IIM Ahmedabad, India. His research interests lie in Project Scheduling and Operations Management with specific focus on retail, health and infrastructure. His email address is sverma@iimahd.erent.in and website address is http://www.iimahd.ernet.in/faculty-and-research/faculty-profile.html\&user_id=90.

ASHISH GUPTA is an alumnus of Department of Mechanical Engineering, Indian Institute of Technology Mumbai, India. Currently, he is a professor at FIITJEE, Gurgaon, India. His email address is ashishguptaiitb@gmail.com. 